\title{
AS FASES HISTÓRICAS DO PENSAMENTO LATINO-AMERICANO E HISPÂNICO
}

\section{THE HISTORICAL PHASES OF LATIN AMERICAN AND HISPANIC THOUGHT}

\author{
Carlos A. Gomes ${ }^{1}$ \\ Recebido: $12 / 2017$ \\ Aprovado: 04/2018
}

\begin{abstract}
Resumo: Na generalidade, pode estabelecer-se um conjunto de marcos histórico-filosóficos que abrangem os principais momentos da evolução das ideias na América Latina, de tradição hispânica. Tendo em conta o critério formulado por Carlos Beorlegui, a criação filosófica assume uma dimensão práxica e decorre fundamentalmente, na época actual, mais da discussão e correlação de problemas concretos, do que da formulação de perspectivas ou de construção teóricas de sistemas. A reflexão filosófica na América Latina sempre obedeceu à discussão de determinados problemas de cunho mais prático e existencial, os quais atravessaram fundamentalmente quatro períodos ou marcos históricos. Dir-se-á que as linhas gerais que têm sido uma constante no pensamento latino-americano, se podem tipificar em tendências bem definidas.
\end{abstract}

Palavras chave: Circunstância, Geração, Identidade, Pensamento latino-americano.

\begin{abstract}
In general, a set of historical-philosophical milestones can be established, covering the main moments of the evolution of ideas in Latin America, from the Hispanic tradition. Taking into account the criterion formulated by Carlos Beorlegui, the creation Philosophical assumption takes on a praxical dimension, and is fundamentally, in the present time, more of the discussion and correlation of concrete problems, than of the formulation of theoretical perspectives or construction of systems. Philosophical reflection in Latin America has always followed the discussion of certain problems of a more practical and existential nature, which have fundamentally crossed four periods or historical milestones. It will be said that the general lines that have been a constant in Latin American thought can be typified in well-defined trends.

Keywords: Condition, Generations, Identity, Latin american thought
\end{abstract}

\section{A história filosófica do pensamento hispânico}

Na generalidade, podemos efectivamente estabelecer um conjunto de marcos sóciohistórico-filosóficos que abrangem os principais momentos da evolução das ideias na América

\footnotetext{
${ }^{1}$ Universidade Nova de Lisboa, Faculdade de Ciências Sociais e Humanas. Doutorado em Filosofia (área da especialidade: Filosofia da Cultura),pela Faculdade de Ciências Sociais e Humanas da Universidade Nova de Lisboa. investigador integrado na Faculdade de Ciências Sociais e Humanas (CHAM - Centre for the Humanities da FCSH/NOVA) no grupo de investigação 'Cultura e história do pensamento hispânico e ibero-americano'. cgomes@fcsh.unl.pt
} 
Latina, de tradição hispânica. Este artigo tem como fonte de inspiração a versão ampliada de "Filosofia na América Latina", que se integrou na Enciclopédia Luso-Brasileira de Filosofia (sob a coordenação de Antônio Paim, Francisco da Gama Caeiro e outros), que foi publicada em Lisboa, pela Editora Verbo em 1992 (5 volumes).

Tendo em conta o critério formulado por Miguel Reale e mais recentemente pelo espanhol Carlos Beorlegui, a criação filosófica assume uma dimensão claramente práxica e concreta, decorrendo fundamentalmente, na época actual, mais da discussão transversal e correlativa de problemas concretos, do que propriamente da formulação sistematizada de perspectivas, ou de construção teóricas de sistemas ${ }^{2}$.

A reflexão filosófica na América Latina sempre obedeceu à discussão de determinados problemas de cunho eminentemente mais prático e existencial, os quais atravessaram basicamente quatro períodos, ou marcos históricos. Dir-se-á que as linhas gerais e fundamentadoras que têm sido uma constante na procura da razão e da identidade no pensamento latino-americano, podem-se tipificar as seguintes tendências:

a) Um filosofar específico nascido da sua própria circunstância e passado, feito de dominação. Por outras palavras, um filosofar feito a partir não só da sua própria circunstância, mas sobre os problemas específicos que configuram o seu solo cultural e social;

b) Um filosofar eminentemente ético e vivencial, nascido de uma matriz estéticoemocional, tipicamente de periferia. Isto significa uma orientação claramente humanística, na medida em que o homem, a sua natureza, e a configuração de uma sociedade justas ao serviço do ser humano, parecem ser os objectivos e os conteúdos mais específicos da generalidade dos intelectuais latino-americanos mais representativos;

c) Um filosofar tendencialmente humanista, nascido das condições de uma dependência historicamente colonial e culturalmente eurocêntrica. A filosofia tem sido considerada na América Latina, uma espécie de flor de importação, pois para ela se tem olhado sempre de fora, num contexto universal, sendo que o objectivo deverá ser apreendê-la e aplicar contextualmente ao próprio solo americano.

\footnotetext{
${ }^{2}$ REALE, Miguel. A Filosofia de Kant no Brasil, São Paulo, Revista dos Tribunais, 1951; PAIM, Antônio. O estudo do pensamento filosófico brasileiro. $1^{a}$. Edição. Rio de Janeiro,Tempo Brasileiro, 1979.
} 
Em termos históricos podemos delimitar os períodos filosóficos na América latina, em quatro grandes eixos ${ }^{3}$ :

a) Período colonial;

b) Período do independentismo libertacionista (face às metrópoles europeias (mais ou menos até 1830);

c) Período da normalização das instituições republicanas (na América espanhola), ou imperiais e republicanas (no Brasil), até fins do século XIX; e, finalmente,

d) Período contemporâneo do século XX (e XXI).

II

\section{O Período colonial}

Em relação ao primeiro grande marco, este estende-se de 1492, data da descoberta da América, até aos finais do século XVIII. Nele, a problemática filosófica marcante na libertacionistareflexão latino-americana, corresponde à formulação de uma antropologia e de uma ética à luz de uma perspectiva transcendentalista ou ontológica ${ }^{4}$ concebida no contexto dogmático da Segunda escolástica espanhola e portuguesa, pautadas fundamentalmente pela "Ratio Studiorum” (1598).

Representante desse período foi o frade Alonso de la Vera Cruz, que elaborou, em 1554, na Real e Pontifícia Universidade do México, o primeiro Tratado de Filosofia na América. Outros autores hispano-americanos de nomeada, no século XVI, foram os padres Bartolomeu de Ledesma, Pedro Ortigosa e Antonio Rubio, que no México e no âmbito do ensino universitário desenvolveram as teses fundamentais da Segunda escolástica.

O aspecto central da reflexão filosófica deste período, foi procurar encontrar uma justificação plausível para a evangelização dos aborígenes, no contexto da grandiosa acção de conquista predatória desencadeada pelos Impérios espanhol e português. Isso não impediu, no entanto, que muitas críticas fossem endereçadas por alguns pensadores do período, à cupidez

\footnotetext{
${ }^{3}$ GOMES, Carlos A. O pensamento hispânico e aproblemática da identidade cultural, Aufklarung, V.3 № 1 , Abril 2016, p.171.

${ }^{4}$ A perspectiva transcendentalista (formulada por Platão e sistematizada por Aristóteles) consiste num ponto de vista último do conhecimento, que parte do pressuposto de que a razão humana é capaz de atingir a coisa em si, ou a substância ultima do real. Distingue-se da perspectiva transcendental (formulada por Hume e Kant), que parte do pressuposto de que a razão humana apenas tem acesso aos fenómenos, e não à substância das coisas (númenos).
} 
dos conquistadores, a qual contrariava o direito consuetudinário castelhano e as Leis de Índias, merecendo serem lembradas aqui as referidas nos 'Sermões' do Padre António Vieira e nos escritos do padre Bartolomé de Las Casas.

\section{III}

\section{O Período do independentismo libertacionista}

Um problema básico abordado nesta fase, foi o relativo à fundamentação das lutas em prol da libertação dos novos países relativamente às suas antigas metrópoles. Três fontes teóricas passaram a inspirar a meditação latino-americana desse período, no terreno político: a da Segunda escolástica, que no tocante à discussão dos fundamentos da soberania popular se alicerçava na obra De legibus ac de Deo legislatore (1613), do jesuíta espanhol Francisco Suárez; a do democratismo formulado nas obras de Jean-Jacques Rousseau, A origem da desigualdade entre os homens (1753) e Do contrato social (1762), obras estas que inspiraram amplamente a Revolução Francesa. Por último, a terceira fonte de inspiração foi a da teoria do governo representativo, tematizado por John Locke no seu Segundo tratado sobre o governo civil (1689).

As ideias do liberalismo anglo-americano nunca penetraram directamente no universo latino-americano, tendo para isso sido fundamental a acção e o pensamento dos denominados doutrinários franceses (François Guizot, em particular), bem como dos precursores destes (Madame de Staël), como destacou, com muita propriedade, o conhecido pensador espanhol José Ortega y Gasset ${ }^{5}$.

Os prolegómenos das lutas de independência na América espanhola foram animados, em boa medida, pela meditação da Segunda escolástica. Não há dúvida quanto à inspiração em Francisco Suárez, por exemplo, dos conjurados hispano-americanos do final do século XVIII (nas revoltas dos denominados “comuneros” na Nova Granada), bem como dos “conjurados mineiros" no Brasil do mesmo período, dos precursores da independência neogranadina Camilo Torres e António Nariño, ou das reivindicações independentistas e libertárias do padre Hidalgo, no México.

Já os processos de independência sofreram, paulatinamente, a influência quer do aspecto democrático rousseauniano (que constitui o cerne do pensamento político de Simón

\footnotetext{
${ }^{5}$ GUIZOT, François. Historia de la civilización en Europa. (Prólogo de José Ortega y Gasset), tradução para o espanhol de Fernando Vela). $3^{\text {a }}$ edição, Madrid, Alianza Editorial, 1990.
} 
Rodríguez e do seu discípulo, o grande libertador Simón Bolívar), quer da teoria lockeana do governo representativo (que animou, por exemplo, o general colombiano Francisco de Paula Santander e, principalmente, o grande teórico luso-brasileiro Silvestre Pinheiro Ferreira, o qual formulou as bases da prática parlamentar do Império brasileiro na obra intitulada Manual do cidadão num governo representativo, de 1834.

A discussão das bases teóricas da libertação relativamente às metrópoles espanhola e portuguesa, abrangeu um significativo trabalho teórico, no qual esteve presente uma metafísica formulada em bases modernas, aberta à ideia de 'sistema' (como é o caso das Preleçcões filosóficas de Silvestre Pinheiro Ferreira, de 1813). A filosofia deste autor permitiu a superação do positivismo embutido no empirismo mitigado, que constituiu a doutrina imperante em Portugal no ciclo pombalino, e no Brasil, nos primórdios do século XIX. Já na América espanhola prevaleceu, neste período, a influência do utilitarismo de Jeremy Bentham, bem como a filosofia de Condillac, que foi adoptado como texto oficial em Bogotá, a partir de 1825.

Cabe aqui recordar que na perspectiva do uruguaio Arturo Ardao (1912-2003), expressas nomeadamente nas obras 'Romania y América Latina' (1991) e 'Génesis de la idea y el nombre de América Latina' (1980), existe uma matriz românica em toda a cultura sulamericana. A sua substância principal é a condição de uma predominância étnico-cultural de uma 'mestiçagem' diversificada.

A bem dizer, e pela dicotomia anteriormente salientada (empirismo / utilitarismo) segundo o pensador uruguaio, não existiria uma só América, mas quatro! Estas pluralidades geográficas, políticas. linguísticas e étnicas, estariam subsumidas em quatro tipos: o inglês, o francês, o espanhol e o português. E a partir destes quatro tipos, a América reduzir-se-ia a duas grandes classes: uma América anglo-saxónica de tradição inglesa, e outra América, latina, de tradição românica.

Devido a este conglomerado étnico saxónico-românico e a uma carga linguístico-física bem definidas, a América seria, pela sua própria natureza, essencialmente bipolar. A herança latina, contudo, desenvolvida por um padrão essencialmente ibérico, acaba por condicionar a evolução e o desenvolvimento das tradições locais e do modus vivendi dos povos autóctones.

IV

\section{O Período da normalização das instituições}


Entre 1830 e o final do século XIX formularam-se filosofias que permitiram a consolidação das novas instituições. No contexto ibero-americano, as instituições consolidaram-se parcialmente no âmbito da discussão de uma filosofia liberal, em contraposição ao democratismo rousseauniano e ao tradicionalismo conservador. Radicais como Ezequiel Rojas contrapõem-se, na Nova Granada, por exemplo, a liberais moderados como o colombiano José Maria Samper (1828-1888) ou a tradicionalistas clássicos como Sergio Arboleda. Ao contrário do que aconteceu na América portuguesa, a América espanhola não conseguiu formular uma filosofia que inspirasse a prática da representação e que permitisse dar estabilidade às novas Repúblicas, que se dilaceraram em guerras civis sem fim.

A este propósito, desenvolveu-se uma aguda discussão em torno do binómio herança ibérica/atraso cultural, bem semelhante à efectivada em Portugal pela Geração de 70, nas memoráveis Conferências do Casino. Os principais autores que tomaram parte nessa polémica foram os chilenos Esteban Echeverría, José Victorino Lastarria e Francisco Bilbao, e os pensadores argentinos Juan Bautista Alberdi (1810-1884) e Domingo Faustino Sarmiento (1811-1888).

Mas seria o positivismo que inspirou a síntese filosófica que deu alicerce às instituições, a partir de 1870. Os principais teóricos dessa corrente foram José Ingenieros (Argentina/Uruguai, 1877-1925), Enrique José Varona (Cuba, 1849-1933), Justo Sierra (México, 1848-1912), Carlos Vaz Ferreira (Uruguai, 1872-1958), Valentin Letelier (Chile, 1852-1919), Gil Fertoul (Venezuela, 1861-1943) e Eugenio de Hostos (Colômbia, 18391903).

Em geral, a versão do positivismo que prevaleceu na América Latina, foi uma heterodoxa mistura de krausismo espanhol, caudilhismo e comtismo, temperada, todavia, por influências espiritualistas e vitalistas. A influência do krausismo na América latina é particularmente notória na Argentina, pautando-se como um discurso englobante e eclético e não se confinando ao modelo estigmatizado do cientismo objectivista. O krausismo é, acima de tudo um modelo humanista, vitalista e pedagógico, cuja fundamentação encontramos bem representada no trabalho desenvolvido por Carlos Norberto Vergara (1859-1929).

Este krausismo argentino radicou nos esforços de Francisco Giner de los Rios (18391915) que se constituiu como o grande divulgador de K. Krause, em Espanha.

O final do século XIX conheceu importante reacção ao positivismo em vários países. Assim, encontramos na Argentina as contribuições de Coriolano Alberini (1886-1960) e Alejandro Korn (1860-1936), no México as de José Vasconcelos (1882-1959) e Antonio Caso 
(1883-1946), no Perú, a de Alejandro Deustua (1849-1945), e na Colômbia, a de Danilo Vélez (1920-?). Em geral, essas reacções criticam, no positivismo, o seu conteúdo cientificista, bem como a feição caudilhista dos regimes surgidos à sua sombra.

Numa perspectiva idealista-vitalista,não podemos deixar de referir o extraordinário contributo do uruguaio José Enrique Rodó (1872-1917).

O conceito de cultura (conhecida como arielismo) é o elemento chave neste autor, e é compreendido de uma forma bastante particular. Trata-se de uma concepção aristocrática de cultura ligada ao belo, à experiência estética e à actividade intelectual desinteressada. A crítica ao capitalismo 'americano' é, deste modo, a crítica à massificação, vulgaridade e banalidade utilitaristas, modernas. O ideal de Rodó, seria um 'regresso às origens' - a Grécia Antiga - onde o Homem fosse encarado, não como um mero objecto desqualificado e coisificado, mas sim como um ser integral e total, no qual as suas faculdades fossem uma só. O que Rodó apelida 'racional' (em Ariel), seria a possibilidade de recomposição dos trabalhos manual e intelectual, separados pela sobre-especialização moderna.

Essa seria a verdadeira cultura, que permitiria ao indivíduo uma existência genuinamente 'desinteressada' e pura. Por isso, segundo José Enrique Rodó, a importação dos padrões norte-americanos representaria uma ameaça aos povos e à 'originalidade insubstituível do seu espírito', sendo este pensador um verdadeiro arauto da problemática existencial pós-Moderna. Em pleno século XX, surge a figura incontornável de José Ortega y Gasset, o qual coloca uma questão ampla e extraordinariamente complexa: “O que é a Espanha?".

O século XX terá, na verdade e em Espanha, um papel decisivo para toda a América latina. São publicadas obras que levam o pensamento hispânico a todo o mundo, entre as quais se poderiam destacar, Vida de Don Quixote e Sancho (1905) e Sentimento Trágico da Vida (1914), de Ortega y Gasset e Unamuno, respectivamente, e A Filosofia do Homem que trabalhava e que jogava (1914) de Eugênio D’Ors. E quais os polos dessa realidade? Basicamente dois - Madrid e Barcelona!

A Universidade de Madrid irá ser a fonte de referência e polo aglutinador daquilo a que se denominará Escola de Madrid, tendo Ortega y Gasset como precursor. Dela irão surgir, entrando nos séculos XX e XXI, pensadores integrais (humanistas) como Julián Marias, o discípulo mais jovem de Ortega, Xavier Zubiri, Manuel Garcia Morente, Fernando Vela, José Gaos, Maria Zembrano, e Recasseno Siches. Outro grupo de grandes filósofos e pensadores científicos, seria oriundo da chamada Escola de Barcelona, com Jaime Huntar e Joaquim Xirau como as principais referências. 
$\mathrm{Na}$ verdade, quase se pode afirmar que Ortega y Gasset é autenticamente o Platão espanhol. A sua forma inovadora de pensar e fazer pensar, determina que a tarefa prioritária deve ser a de 'europeizar a Espanha e espanholizar o mundo'. Surge, a partir da escola de Gasset, um pensamento eminentemente hispânico sobre o neo-kantismo, a fenomenologia, o existencialismo, o historicismo, a filosofia dos valores e a lógica simbólica. A Espanha passa a identificar-se com o conjunto dos países latino-americanos, na sua linguagem própria e na sua problemática específica.

Em 1923, Ortega y Gasset funda a célebre Revista de Occidente (publicada até 1936) e incorpora ao pensamento espanhol, todas as questões intelectuais europeias, traduzindo e divulgando obras marcantes de diferentes latitudes.

Em 1948, com Julián Marias, Ortega y Gasset funda, em Madrid, o Instituto de Humanidades. Contradizendo o famoso filósofo alemão Heidegger, evita neologismos, que achava desnecessários, voltando-se antes para as expressões usuais do espanhol, preferindo usar metáforas, já que eram consideradas belas e facilitavam mais a compreensão do pensamento filosófico complexo e abstracto!

Ortega y Gasset é, assim, o claro exemplo do filósofo anti-pedante que simbolizava o ethos natural e espírito comunitarista da hispanidade, mesmo tendo em conta que dominava várias línguas, como o grego, o latim, e o alemão, e possuía uma cultura superior. Por isso o filósofo espanhol dizia que 'a cortesia do filósofo é a clareza'.

Ortega y Gassset personificava o orador sapiente e modesto, desejando mais do que tudo, ser naturalmente inteligível e compreendido. Eu diria, Ortega foi, pois, a imagem da razão vital, colocando nas palavras e nos gestos, a emoção e a cordialidade eminentemente latinas!

\section{V}

\section{O Período Contemporâneao - da Filosofia da Libertação ao interculturalismo}

Muito variadas são as correntes desenvolvidas pelos pensadores latino-americanos neste período. Mais do que mencioná-las exaustivamente, podemos fazer apenas referência a alguns autores, bem como aos principais problemas discutidos. O historicismo e a fundamentação do conhecimento e da liberdade numa perspectiva transcendental, herdeira do criticismo kantiano, foi a tarefa de que se incumbiu a Escola do Recife, no Brasil, no final do 
século XIX. Dela sairia o já referido esforço de Carlos Vergara em reflectir sobre a questão vital, e donde emanaria o krausismo humanista argentino.

No contexto da discussão acerca dos fundamentos transcendentes da identidade social e pessoal, podemos destacar a contribuição dada pelo argentino Francisco Romero (18911962), o qual visa fundamentalmente indagar a natureza e peculiaridade da 'alma argentina'.

Tributário do vitalismo de Dilthey e da axiologia de Scheler, Romero define a pessoa como 'absoluta transcendência'. Na trilha da tradição humanista ocidental, Daniel Villegas assume, no México, a defesa de uma antropologia condizente com a dignidade da pessoa, em especial no que toca aos desdobramentos dessa concepção no terreno político, com uma crítica bastante bem fundamentada à tradição positivista do poder. Numa posição próxima à do culturalismo de Miguel Reale, destaca-se também no campo da filosofia do direito, o mexicano Recasens Siches.

Outros pensadores que merecem referência são os argentinos Risieri Frondizi (19101985) e Carlos Astrada (1894-1930).

Ao longo da sua carreira e em toda a sua obra, Frondizi, mostra um indesmentível interesse em esclarecer os problemas sobre o ser humano, a sua conduta, ética e valores axiológicos. Para si, a teoria filosófica tem um sentido definido face a uma praxis e a um estilo de vida. Este estilo é de inspiração socrática, e está virado para a essência do viver e do com-viver, como diria Ortega.

Por sua vez, Astrada foi um autodidacta que desenvolveu uma grande estima pelos estudos filosóficos, estudando na Alemanha com Max Scheler e construindo uma forte relação pessoal com Heidegger, Cassirer, Nicolai Hartmann e outras figuras ilustres da filosofia naquele período. A publicação do 'Ser e tempo', em 1927, constituiu uma referência central no pensamento e ideário de Astrada. Desenvolveu uma filosofia existencialista peculiar, assentando a sua reflexão sobre os conceitos de 'temporalidade', 'dialectica', 'liberdade', 'acção' e 'praxis', mas inspirada na sua fonte heidegeriana.

Em termos de produção uruguaia, não nos podemos esquecer de Arturo Ardao (19122003). Foi o introdutor do conceito de 'unionismo latino-americano', raíz do pensamento sobre a história das ideias na América latina.

$\mathrm{Na}$ sua obra 'El unionismo hispanoamericano', Ardao expõe numa sólida base experimental e profundidade analítica, as ideias fundamentais dos movimentos libertadores de princípio do século XIX, ou seja, a base doutrinal das suas grandes referências - Bolívar, Saint Martin e O'Higgins. 
A partir de 1986, Arturo Ardao desenvolve um estudo histórico sobre a ideia geral de 'americanismo', desdobrando-a nos conceitos de 'pan-americanismo' e 'latinoamericanismo', a partir das suas origens nos EUA e em França, respectivamente. Dialecticamente ambos passam a ser caracterizados no campo político-ideológico. O termo 'latinoamericanismo' começa a ter um uso mais profícuo para designar o sentimento de reacção defensiva face ao expansionismo norte-americano, enquanto na Europa o mesmo tende a significar uma mensagem 'nacionalista' contra o domínio cultural anglo-saxónico, confome advogava o seu conterrâneo José Enrique Rodó.

Com efeito, 'latinoamericanismo' pressupõe um vínculo estreito com a cultura hispano-americana de raíz latina. Para Ardao, o conceito 'latino-americanismo' é uma corrente que veio a desencadear um 'americanismo' cujo sentido continha já em estado latente, por assim dizer, os futuros sentidos de 'pan-americanismo' e 'latino-americanismo', desenvolvidos a partir de 1890. Para o filósofo uruguaio, toda a história do conceito, na sua significação etimológico-filosófica constituiu o 'leitmotiv' do pensamento crítico latinoamericano.

A diferença entre os conceitos, radica no seu conteúdo. Enquanto o hispanoamericanismo constitui mais um regionalismo, o latino-americanismo foi interpretado fundamentalmente como um projecto nacionalista até finais do séc. XIX, tendo em vista um horizonte de expectativas políticas futuras. Daí que surgisse igualmente o termo 'unionismo', nas suas vertentes hispano-americana e latino-americana tendo sempre em vista uma consciência independentista, ou no dizer de Ardao, 'a la gran comunidad patriótica y nacional llamada a desprenderse del Imperio español'. A bem dizer, segundo o pensador uruguaio, não existiria uma só América, mas quatro, conforme já foi salientado neste artigo. Em função destas diferenças, não podem existir visões redutoras eurocêntricas, mas sim um diálogo intercultural que exclua quaisquer formas de assimilação ou aculturação.

Mais recentemente e pós-anos 80, pode-se considerar que a filosofia intercultural constitui uma etapa evolutiva da filosofia da libertação latino-americana, dominante a partir dos anos 60 e dinamizada pelo argentino Enrique Dussel (1934-?). Iniciada a partir das reflexões de Raul F. Bettancourt (1946-?) e desenvolvida igualmente por outras figuras do pensamento sul-americano e mesmo europeu, como Horácio Cerutti (Argentina), Franz Hinkelammert (Costa Rica), Léon Olivé (México), Franz Wimmer (Áustria) e Heiz Kimmerle (Alemanha). Esta nova forma de reflexão filosófica focaliza o conhecimento numa base mais 
ampla e abrangente (contextual), integrando e não excluindo, os vários 'pensamentos' e diferentes culturas.

Em função deste novo paradigma, a filosofia intercultural manifesta uma dimensão crítica muito acentuada, pois tenta dar resposta prática e ser uma alternativa aos problemas existenciais, integrando questões ligadas à ontologia (estrutura da realidade), epistemologia (cognoscibilidade da realidade), ética (normas e valores) e política (organização da sociedade).

Contrariamente ao que predomina na tradição filosófica ocidental, de pendor centralista, racionalista e etnocêntrica, a filosofia intercultural incorpora todas as particularidades (circunstâncias) e tradições regionais (contextos), focalizando-se numa dimensão plural e não homogénea do conhecimento e da cultura humanas. Poderíamos sintetizar nesta dimensão, três caracteristicas essenciais:

a) necessidade de superação do privilégio concedido à visão europeista da história da filosofia ocidental, enquanto 'pensamento ou paradigma únicos';

b) necessidade de descoberta de outras e múltiplas origens, de abertura a outras tradições (mito, religião, cosmogonia...);

c) c) necessidade de estabelecer uma base dialógica entre as diferentes tradições, a partir dos princípios universalistas do respeito, tolerância e conhecimento mútuo.

O objectivo último da filosofia intercultural, baseada também no princípio da interdisciplinaridade é, na verdade, dar novas respostas e constituir-se como uma alternativa aos processos e desafios actuais da globalização económica e homogeneização cultural.

Urge não nos deixarmos apagar na objectivação e desumanização, fazendo, pelo contrário, com que o homem seja uma parte activa e integrante do todo (cosmos), e não uma parte decartável neste processo de dominação e reducionismo existencial. Urge, pois, recuperar o 'ethos' ibero-latino, comunitarista e solidário!

Em suma, não se trata de excluir 'o outro', mas de 'interpretá-lo', concebendo a vida e a cultura como um enriquecimento dinâmico e dialéctico, de transformação e libertação do homem, visando a sua autonomia e consciencialização racionais ${ }^{6}$. Os mais importantes historiadores contemporâneos das ideias são o argentino Arturo Andrés Roig (1922-2012); os mexicanos José Gaos (1900-1969) e Leopoldo Zea (1912-2004); o uruguaio Arturo Ardao, já referido antes, o boliviano Guillermo Francovich (1901-1990); os peruanos Augusto Salazar

\footnotetext{
${ }^{6}$ GOMES, Carlos A. Vide a este propósito e numa visão mais abrangente, o artigo http://filcarlos.com/figuras-da-filosofia-intercultural-latino-americana/
} 
Bondy (1925-1974) e Francisco Miró Quesada (1949-?); o venezuelano Ernesto Vallenilla (1925-?) ${ }^{7}$ e o hispano-salvadorenho Ignacio Ellacuria (1930-1989).

O peruano Augusto Salazar Bondy foi um dos teóricos da chamada FL (filosofia da libertação). Um dos aspectos em que mais reflectiu, foi exactamente naquilo a que se viria a chamar a 'filosofia hispanoamericana' e cujas ideias são negativas, quanto à sua natureza própria e original. Em inúmeras obras, em particular em '¿Existe una filosofía en nuestra América?, Bondy manifesta a sua ideia-chave de que o pensamento filosófico latinoamericano está desprovido de um carácter próprio, sendo puramente imitativo e anatópico. A sua teoría sobre a cultura da dominação, permite-nos compreender melhor a necessidade de uma cultura verdadeiramente livre, sem quaisquer dependencias, sejam elas política, económica ou cultural.

Por sua vez, Arturo Roig, foi um continuador da tarefa iniciada por Leopoldo Zea, de impulsionar a criação de um projecto de uma filosofía ibero-americana a partir de uma sistemática e profunda reflexão sobre a história das ideias no continente (sul) americano. A finalidade era elaborar uma filosofia própria, específica, atendendo ao contexto sócio-cultural dos países latino-americanos, na sua globalidade. Esta filosofía foi entendida como uma teoría da liberdade, uma 'filosofia da libertação', formulada, desde logo, como teoría crítica do pensamento latino-americano. Esta crítica radical às 'filosofias da consciência' constitui o ponto de partida do seu projecto, incorporando a análise do 'ideológico' no discurso filosófico, ligando este, por sua vez, ao 'discurso político'.

Por outro lado, Arturo Roig interpretou os conflitos actuais com argúcia, profundidade e compromisso. Exemplos disso foram a sua crítica à globalização neoliberal, às políticas do capitalismo na sua fase tardia, e pugnou pela construção de uma democracia participativa, pela valorização do papel activo do sujeito moral na sociedade civil, e pela universalidade na esfera da justiça. A filosofía, tal como a entende Arturo Roig, parte sempre de um compromisso vital, e nutre-se de um desejo radical de emancipação e liberdade.

Segundo Salazar Bondy, o pensamento filosófico latino-americano ou qualquer outro com propósitos explicativos similares, oferecem, um selo de negatividade, uma consciência ilusória que o impede de assumir a sua própria inquietação histórico-existencial. Devido ao

\footnotetext{
${ }^{7}$ Graduou-se em Filosofia e literatura na Universidade Central da Venezuela, aprofudando os seus estudos nas Universidades alemãs de Gottingen, Freiburgo e Munique, onde foi aluno de Heideger. Vallenilla realizou estudos importantes que contribuiram para uma melhor compreensão acerca do problema do 'ser' latinoamericano numa perspectiva ontologica e existencial. Foi autor de El problema de la nada en Kant, sendo editada em castelhano pela conceituada Revista de Occidente (Madrid, 1965) sob recomendação expressa de José Ortega y Gasset. Entre as suas obras de maior fôlego, estão Del hombre y su alienación (1966), Ratio Technica (1983), e Fundamentos de la Metatécnica (1990).
} 
seu carácter redundante e copiado de modelos europeus, a consciência latino-americana tornou-se, segundo ele, uma consciência alienada e alienante, que deu ao homem destas latitudes uma imagem superficial do mundo e da vida. Claro que este aspecto culturalmente deficitário tem uma causa histórica irrefutável: a imposição de uma filosofia 'estranha' pelo conquistador europeu. Segundo Salazar Bondy, a filosofia hispanoamericana constituiu-se, portanto, ao longo de sua história, como um produto sem originalidade e autenticidade, como imitação de conteúdos filosóficos alheios (europeus), surgidos num contexto histórico diferente.

Importa dizer que o já referido José Gaos foi discípulo de José Ortega y Gasset, o pai da filosofia hispânica. Nessa natural influência intelectual, há como que uma transmissão 'genética' para Gaos, a vários níveis:

- fizeram ambos uma filosofia no singular;

- tinham ambos uma cultura superior, vasta e diversificada, quer ao nível clássico quer moderno;

- aliavam o ensino da filosofia teórica com a construção de um filosofar crítico, sob forma de cursos, seminários e conferências;

- manifestaram níveis de comunicabilidade imensos e autênticos;

- tinham uma enorme capacidade de sugestão expressiva e de persuasão genuínas.

A partir destes presupostos, pode dizer-se que Gaos mudou o panorama cultural mexicano, trazendo a semente dos ensinamentos da Escola de Madrid onde pontificava o seu mestre Ortega y Gasset. Forjou uma nova filosofia (americana), assente no património da história das ideias latino-americanas e na sua circunstancialidade (históricas, sociais e culturais).

Foi através da linha coerente dos princípios da circunstância, da consciência e do compromisso, que José Gaos tomou o México e a América Latina como pontos de partida de uma história universal, a qual também, foi em parte, a dele.

Quanto a Zea, o seu ideário resumiu-se à simples mas importante questão: será possível construir-se uma filosofia sul-americana?

Para isso ter-se-ia que abordar a questão por dois ângulos, os quais estão intimamente ligados: o Homem e o Pensamento, ou consciência. O conceito de 'Homem' em Leopoldo Zea configura uma visão relativista, culturalista e aberta, cuja peculiaridade e diferença deve ser o 
meio de promover autênticas relações de igualdade, desmascarando todas e quaisquer justificações de dominação. Não há homens mais universais que outros, mas apenas homens diferentes e particulares. A ideia de liberdade do pensador mexicano é simétrica à da dignidade, solidariedade e igualdade existencial, cuja vinculação a legitima com a procura da finalidade histórica do Homem. Contudo, faltam ainda estudos mais abrangentes sobre a história do pensamento filosófico na América Latina, terreno no qual é justo mencionar, nos últimos decénios, três realizações importantes.

VI

\section{Os estudos actuais do tema, em Portugal}

$\mathrm{Na}$ actualidade e em termos de abordagem da problemática filosófica no universo latino-americano, podemos referir, em primeiro lugar, a clássica obra do espanhol José Ferrater Mora, intitulada Diccionario de Filosofia ${ }^{8}$, na qual os autores ibéricos e iberoamericanos são meticulosamente estudados no seio da tradição filosófica universal.

Em segundo lugar, dever-se-á lembrar o extraordinário trabalho realizado na Universidade da Geórgia nos Estados Unidos, a partir de 1986, pelo estudioso de origem espanhola, José Luis Gómez Martínez, à volta do seu Projeto Ensayo Hispânico ${ }^{9}$.

Também em Portugal, é justo recordar a significativa realização editorial sob a coordenação de António Paim, Francisco da Gama Caeiro e outros investigadores, da Universidade Católica Portuguesa, na Enciclopédia Luso-Brasileira de Filosofia ${ }^{10}$ a qual versou o pensamento filosófico dos autores ibéricos e ibero-americanos, no contexto da história da cultura ocidental.

Mais recentemente, e no âmbito do Centro de Humanidades - CHAM, um grupo de investigadores de Pensamento Hispânico, da Faculdade de Ciências Sociais e Humanas da Universidade Nova de Lisboa, sob a coordenação de José Esteves Pereira, dedica-se desde 2014, ao Projecto Gerações Hispânicas, onde é analisada e aprofundada toda a dinâmica relacionada com a teoria das ideias no mundo ibero-latino-americano ${ }^{11}$. São integrantes desta equipa de investigação, dedicando-se especificamente a um bloco concreto do mosaico

\footnotetext{
${ }^{8}$ FERRATER Mora, José. Diccionario de Filosofía. Madrid: Alianza Editorial, várias edições, 4 volumes.

${ }^{9}$ As pesquisas feitas pela equipe internacional de estudiosos do pensamento ibérico e ibero-americano aparecem no Portal do Projeto 'Ensayo Hispánico', no endereço: www.ensayistas.org.

10 PAIM, Antônio; CAEIRO, Francisco da Gama e outros, Enciclopédia Luso-Brasileira de Filosofia. Lisboa/São Paulo: Editora Verbo, 1989-1992, 5 volumes.

${ }^{11}$ Vide http://www.cham.fcsh.unl.pt/li_apresenta.aspx?linha=13, http://www.cham.fcsh.unl.pt/li_projectos.aspx
} 
hispânico, o já referido coordenador, José Esteves Pereira, e Cecília Barreira (Brasil), Carlos A. Gomes (América Latina), Margarida I. Amoedo (Espanha), Julio R. Silva e Teresa Lousa (Portugal).

Destaque para as conferências e workshops que, neste âmbito, são organizadas naquela universidade.

\section{Referências}

BETANCOUT, Raúl Fornet, Interculturalidade: crítica, diálogo e perspectiva. São Leopoldo: Nova Harmonia, Brasil, 2004.

Interculturalidad y globalización. Ejercicios de crítica filosófica intercultural en el contexto de la globalización neoliberal. Ed. Frankfurt/M.: IKO - San José, Costa Rica, DEI, 2000 .

BETANCOURT, Raúl Fornet e BEORLEGUI, Carlos. Filosofia latinoamericana. Editorial Comares, S.L. Colección Guía Comares, 5, Granada, Espanha, 2014.

GOMES, Carlos A. Filosofia e cultura luso-hispãnica. e-book, EPUB, Wordpress, $1^{\text {a }}$ edição, Lisboa, Portugal, 2014-2017, in www.filcarlos.com

O pensamento hispãnico e a problemática da identidade cultural. Aufklarung, V.3 No 1. Abril 2016, p.171, Paraíba, Brasil, 2017.

GUIZOT, François. Historia de la civilización en Europa. $3^{\mathrm{a}}$ ed. Prólogo de José Ortega y Gasset, Tradução para o espanhol de Fernando Vela. Madrid,Espanha: Alianza Editorial, 1990.

PAIM, António. O estudo do pensamento filosófico brasileiro. Rio de Janeiro:Tempo Brasileiro, 1979.

PAIM, António, CAEIRO, Francisco da Gama [et al]. Filosofia na América Latina. Enciclopédia Luso-Brasileira de Filosofia. Editorial Verbo (5 volumes). Lisboa, Portugal: 1992.

REALE, Miguel. A Filosofia de Kant no Brasil. São Paulo: Revista dos Tribunais, 1951. 